was the elbow or knee. On examining the uterus through the abdominal parietes, I found it firmly contracted, remarkably small and low in the pelvis; the pains at this time were not very active, and the discharge of water had entirely ceased. After a time, the hand, with the palm to the sacrum, slipped into the vagina. Having no longer the slightest doubt, I determined on turning, if possible, but was not able to get so much as the tip of one finger into the uterine cavity, and the attempt was attended with great suffering to the patient. Immediately on the release of the child's hand from the os, the expulsive efforts became exceedingly powerful, and followed each other almost without intermission; and finding that with each the arm was descending, I did not feel justified in using more force, but made up my mind, for the present at least, not to interfere. Gradually the whole arm was protruded, and the point of the shoulder passed under the arch of the pubes, and never receded; the side of the chest now came upon and separated the labia, and the perinæum was fearfully distended. My patient's age being in her favour, (twenty, notwithstanding this was her first labour, I was happily able, by steady support, to save this structure from laceration. A delay of about ten minutes took place before the breach was expelled. I then obtained a purchase in the fold of the thigh, and assisted the delivery of the legs; this being accomplished, there was a cessation of the pains for two or three minutes; they then returned; and having first brought down the left hand, I delivered the head (face to sacrum) in the usual way, without difficulty.

The child (male) was born dead; it measured nineteen inches. I had no opportunity of weighing it, but it was well developed, and of average bulk. The woman has recovered without a bad symptom.

Aldersgate-street, 1852.

\section{ON THE MOBILITY OF ARTIFICIAL EYES.}

\section{Bx A. BOISSONNEAU, EsQ.,}

RNIGHT OF SEVERAL FOREIGN ORDERS, AND MEMBER OF THE MEDICAL SOCIETX OF MUNICH.

THE mobility of the artificial eye is of so much importance in surgical science, that $I$ beg permission to dwell on the subject for a few moments; the more so as, among the many cases in which my new method has been successful, there is a very recent one illustrating it in a remarkable manner.

J. B_ , a groom, and a patient of the Royal London Ophthalmic Hospital, Moorfields, lost his left eye from an accident; the organ is not the least atrophied; the only diminution, and this a very slight one, is a falling in of the cornea. The artificial eye which I made for this man, was applied by himself, and though exactly fitting the bulb, it gave no pain, and the same bulb, carrying with itself the enamel substitute, causes the artificial eye to move within the lids like the sound organ.

The principles upon which this remarkable result rests are the following:-The artificial eyes which emanate from me, are hemispherical capsules, and those made according to the old method are oval shells; the latter pinch the bulb, irritate the conjunctiva and the sclerotica, canse the secretion of mucus and pus, render the orbitar cavity misshapen, produce great stiffness of the eyelids, unavoidable strabismus, and if they move at all, it is in a weak and discordant manner; the face assuming, at the same time, an uncertain and wild look.

The new hemispherical capsules are, on the contrary, segments of spheres, presenting varying sections, and modified in many different ways, according to the peculiarity of the cases. To this new artificial eye is given, for each person, a special spheroidal conformation, and it is adapted according to fixed methods to the pathological changes, which are of course different in each individual.

By this means even very large bulbs may be fitted: this was formerly quite impossible, and a surgical operation was, in such cases, inevitably resorted to. Now, however, a large bulb, far from offering any obstacle to the adaptation of the artificial eye, is, on the contrary, the very thing which yields the greatest advantage to my new method. I have adapted such eyes upon patients of Mr. Dalrymple, where the bulb had even increased by one-sixth.

The mobility of the artificial eye is produced by the movements of the bulb, upon which it is exactly fitted. The artificial substitute is, in fact, carried in all directions between the lids, and moves like the sound eye, owing to the exact proportions which are worked out between the curves of the bulb and those of the enamel, and by the precise adaptation of one upon the other, so that the resemblance between the natural and artificial eyes becomes complete.

Though mobility is indispensable, there ought likewise to be perfect concordance between the enamel and the sound eye. This isochronism is attained by attention being paid to a juxtaposition of the artificial eye with regard to the centre of gravity of the bulb; the enamel substitute then takes of itself the exact horizontal position, which makes it harmonize with the sound eye. These results are mainly owing to the centrifugal force which, by means of the varying thickness of the artificial eye, and the peculiarities of its margins, acts with the assistance of the lids, and guides the enamel shell to the direction which it should take. Thus, and only thus, will the most perfect similitude and concordance be obtained. From the preceding explanations it will be easily understood what an enormous difference there is between a feeble and dis cordant mobility and the isochronism which the art of the ocularist, when well exercised, should always produce.

March, 1852.

\section{A mínor}

OF THE PRACTICE OF

\section{MEDICINE AND SURGERY IN THE} HOSPITALS OF LONDON.

Nulla est alia pro certo noscendi via, nisi quam plurimas et morborum, et dissectionum historias, tum aliorum proprias, collectas habere et inter se comparare.-Morgagnr. De Sed. et Caus. Morb., lib. 14. Procmium.

\section{ROYAL FREE HOSPITAL.}

Fracture of the Femur close above the Knee-joint, with a small Wound of the Articular Cavity not communicating with the broken bones.

(Under the care of Mr. Thomas WakLEx.)

Conservative surgery is in our days decidedly in favour: we see proofs of this fact in all the hospitals which we habitually visit. When patients are brought in dreadfully mangled by machinery, the surgeon makes nice calculation concerning such parts of the limb he may preserve; if joints are diseased, the processes entering into the formation of the articulation are excised, and the member saved from amputation; if bones are carious or necrosed, the ulcerated or dead portions are removed, and the parts are given a chance of taking on a new action and healing; if any portion of the cutaneous surface is deficient, it is filled up by autoplasty; if any part of a limb has taken an abnormal direction, the defect is rectified by division of tendons and subsequent apparatus, with hardly any solution of continuity in the skin; if cicatrices resulting from burns produce ugly and inconvenient contractions, the latter are removed by constant extension, without recourse being had to the knife; varicose veins are relieved by elastic pressure, abscesses are repelled by methodical compression, \&c. \&c. But it becomes sometimes a difficult problem, with certain injuries, to decide whether a conservative attempt may safely be ventured, or whether, for the preservation of life, the limb should be taken off at once.

Though we have much respect and sympathy for the propensity of the day, we cannot conceal the fact that here and there the desire of saving a limb has cost a life; the surgeon should therefore prefer the dictates of his judg. ment to his natural bias; and though his intentions may be praiseworthy, he runs the risk of doing harm whilst endeavouring to do good. Facts sometimes come before the hospital surgeon which strongly impress upon him the necessity of occasional stern dealing. For instance, a patient is admitted with an injury evidently requiring amputation; this, from some reason or other, he refuses, and in a few days he dies. These examples are valuable, for they clearly show that misunderstood leniency might sometimes be extremely baneful.

Mr. T. Wakley's case offers this peculiarity, that the injury to the knee-joint was not considerable, and did not communicate with the fracture; he took advantage of these circumstances; and it will be seen from the following details, noted by Mr. Lane, the house-surgeon, what fluctuations preceded the ultimate success. 